Article

\title{
A Model-Assisted Reduced-Order ESO Based Cascade Controller for Sensorless Control of Independent Gear-Shifting Actuators
}

\author{
Yingchao Zhou (D) and Siqin Chang * \\ School of Mechanical Engineering, Nanjing University of Science and Technology, Nanjing 210094, China; \\ zhouyingchao_njust@163.com \\ * Correspondence: 213101000003@njust.edu.cn; Tel.: +86-025-8431-5451
}

Received: 26 October 2017; Accepted: 7 December 2017; Published: 9 December 2017

\begin{abstract}
Independent gear-shifting actuation systems, which are based on linear electromagnetic actuators (LEMAs), have tremendous potential to minimize the shifting duration of automated mechanical transmission (AMT). A velocity estimator based on the measurements of current is designed to achieve sensorless control of the actuator by using only electrical subsystem, thus avoiding the use of a complete system model that contains mechanical uncertainties. The elimination of the position sensor simplifies the structure of the gear-shifting system and reduces the manufacturing cost. To enhance the robustness of the position control, model-assisted reduced-order extended state observer (ESO) based cascade controller is constructed, which take parameter uncertainties and external load force as the lumped disturbance to observe and compensate them dynamically. Finally, simulation and experimental results are shown to demonstrate the effectiveness of the proposed velocity estimator and control method.
\end{abstract}

Keywords: linear electromagnetic actuator; sensorless control; extended state observer; cascade control

\section{Introduction}

Automated mechanical transmission (AMT) has a mechanical structure similar to manual transmission (MT), and it is equipped with additional clutch and gear-shifting actuation systems to realize automatic control. AMT inherits the advantages of high transmission efficiency and the low cost of MT, and provides convenient operation similar to automatic transmission (AT). AMT has been widely applied in trucks, buses and small cars [1]. However, a poorly designed and controlled AMT may not achieve desired shifting quality.

To improve the performance of AMT, many researchers have focused on control strategies in terms of clutch, engine, shift schedule or integrated driveline control [2-4], while the details of gear-shifting control are seldom studied. The shifting duration is one of the important indices that determine the torque interruption during the gear-shifting process. The key to minimizing the shifting duration is to achieve independent gear-shifting control. Nowadays, different varieties of gear-shifting actuation systems are applied in AMT, such as, electrohydraulic types [5,6], electropneumatic types [7,8], and electromechanical types $[9,10]$. However, these systems are limited by their complex structure and can hardly meet the need to implement independent gear-shifting actuation systems. As a result of advances in permanent magnet materials, power electronics and control technologies, the linear electromagnetic actuator (LEMA) is widely applied to high-speed and high-precision positioning systems, since it is of simple structure and responds quickly [11,12]. An LEMA-based independent gear-shifting actuation system offers tremendous potential for shortening the duration of power interruption, because it provides feasible overlap control of gear-disengaging and gear-engaging phases, which can significantly reduce the shifting time [13]. 
Gear-shifting with the synchronizer is performed by changing the position of the shifting fork according to the appropriate time, i.e., the control of the actuator requires the position information of the actuator as feedback [14]. The most common approach is to install the position sensor on each actuator, but this introduces a number of position sensors, increases the system cost and takes up more installation space. In addition, the position sensors are susceptible to electromagnetic interference when packed in the same shell as the actuators. Once the position sensor fails, the actuation system cannot work normally [15]. In order to overcome these shortcomings, the sensorless control scheme is adopted in this paper. Compared with the separate actuator/sensor systems, sensorless control provides many advantages such as low-cost, simplicity and robustness [16,17]. In this context, a great number of papers have been presented for the piezoelectric actuator [18], induction motor [19,20], permanent magnet synchronous machines [21], etc. Compared to rotating electrical machines, studies of sensorless control for LEMAs are not frequently found in the literature. In [22], an adaptive and optimized switching velocity estimator is designed, but this method only applies to a system that satisfies the persistent excitation conditions. Furthermore, some cascade structures, which combine a position observer with a velocity estimator, are proposed to achieve sensorless control of the electromagnetic system. In particular, the Luenburger observer [23], extended Kalman filter [24] or sliding-mode observer [25] are widely used to estimate the position. However, these approaches require relatively accurate mechanical models that are often hard or difficult to obtain. Currently, sensorless control for LEMAs has been extensively used in industrial applications, such as, active vibration control [26], loudspeaker systems [27] or linear compressors [28,29], but few papers pay attention to the gear-shifting control.

Since the actuator is directly connected to the load, it is easily affected by various uncertainties or disturbances from the complex gear-shifting process. Traditional Proportional-Integral-Derivative (PID) control is only effective under small disturbance conditions with relatively low control precision [30]. The typical disturbance rejection methods, which is used widely in practice, include adaptive control, robust control and sliding model control [31,32]. These control approaches generally achieve disturbance rejection via feedback regulation based on the tracking error between measured outputs and set-points. Thus, they cannot react directly and fast enough in the presence of strong disturbances, although they can finally suppress the disturbances in a relatively slow way [33]. Due to limited shifting duration, an overcomplicated control algorithm is obviously not desirable. The two-degree of freedom controller based on a disturbance observer [10,34] has a simple structure and provides the ability to perform both set-point tracking and disturbance rejection. The extended state observers (ESO) technique was first proposed as part of active disturbance rejection control (ADRC) [35]. The main advantage of the ESO technique is that it can estimate uncertainties in the system with little model information, and it takes parameter uncertainties and external load force as the lumped disturbances [36,37]. With the available state, the reduced-order ESO [38] could be designed to simplify the structure of the observer.

In this paper, a velocity estimator is proposed to achieve sensorless control of independent gear-shifting actuator. A model-assisted reduced-order ESO based cascade control strategy is designed to improve both the robust stability and the transient performance of position control.

The rest of paper is organized as follows. The system overview and the models of LEMA are introduced in Section 2. In Section 3, the detailed design procedure of the velocity estimator is explained. A model-assisted reduced-order ESO based cascade controller is proposed in Section 4. In Section 5, comparative simulations and experimental tests are conducted to verify the effectiveness of the proposed method. Finally, the paper is concluded in Section 6.

\section{System Overview and Modeling}

Figure 1a shows the prototype of the novel independent gear-shifting actuation system. Figure $1 \mathrm{~b}$ shows the schematic diagram of the independent gear-shifting actuation system. Each shifting fork is driven by one LEMA, which can move axially with bi-directional movement to actuate the synchronizer to change gears between three positions (two gear-engaging positions and one neutral position). 
Since the axial inertia of the moving parts is minimized in the shifting mechanism, high response performance could be obtained via the high driving capability of the LEMA. The common approach for the control of the actuator uses the position sensor linked to the actuator as feedback, but this will introduce a number of position sensors, increase the system cost and take up more installation space. Therefore, this paper applies the sensorless control scheme to the position control of the LEMA. A velocity estimator is designed by using only the electrical subsystem, thus avoiding the complete system model that contains mechanical uncertainties.

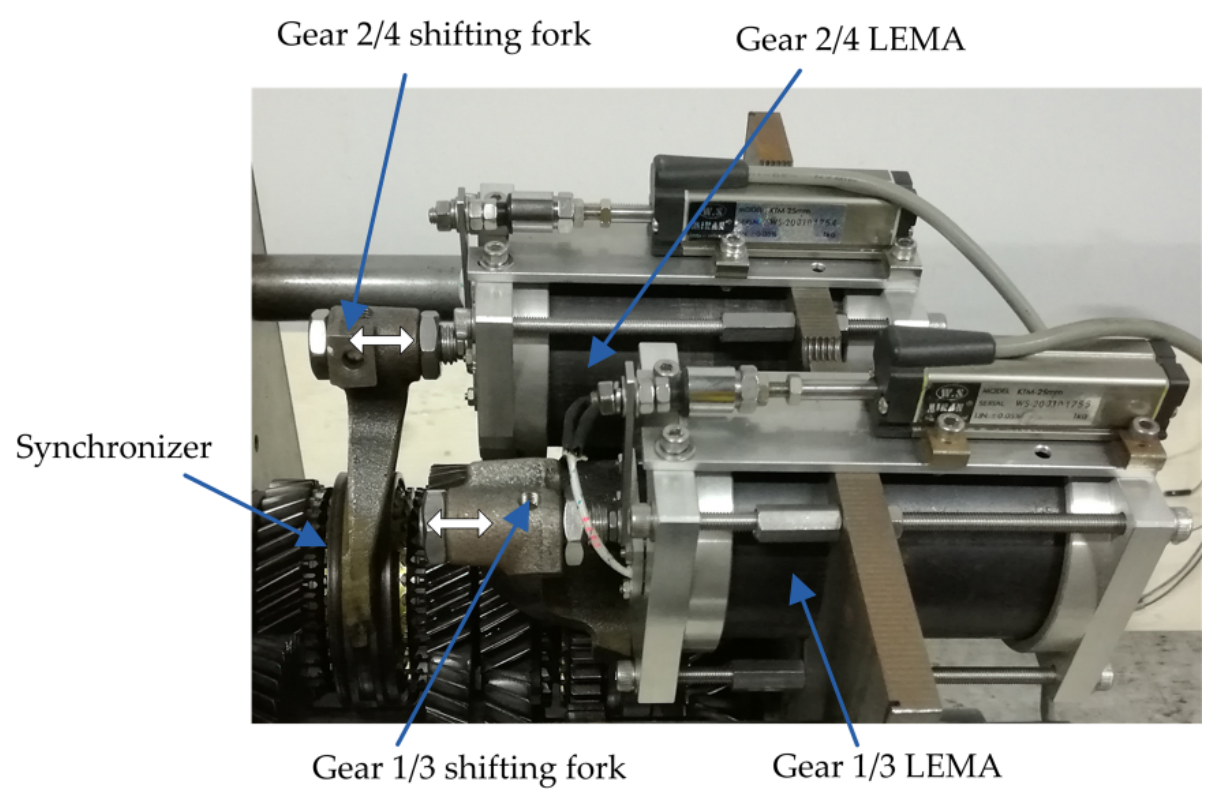

(a)

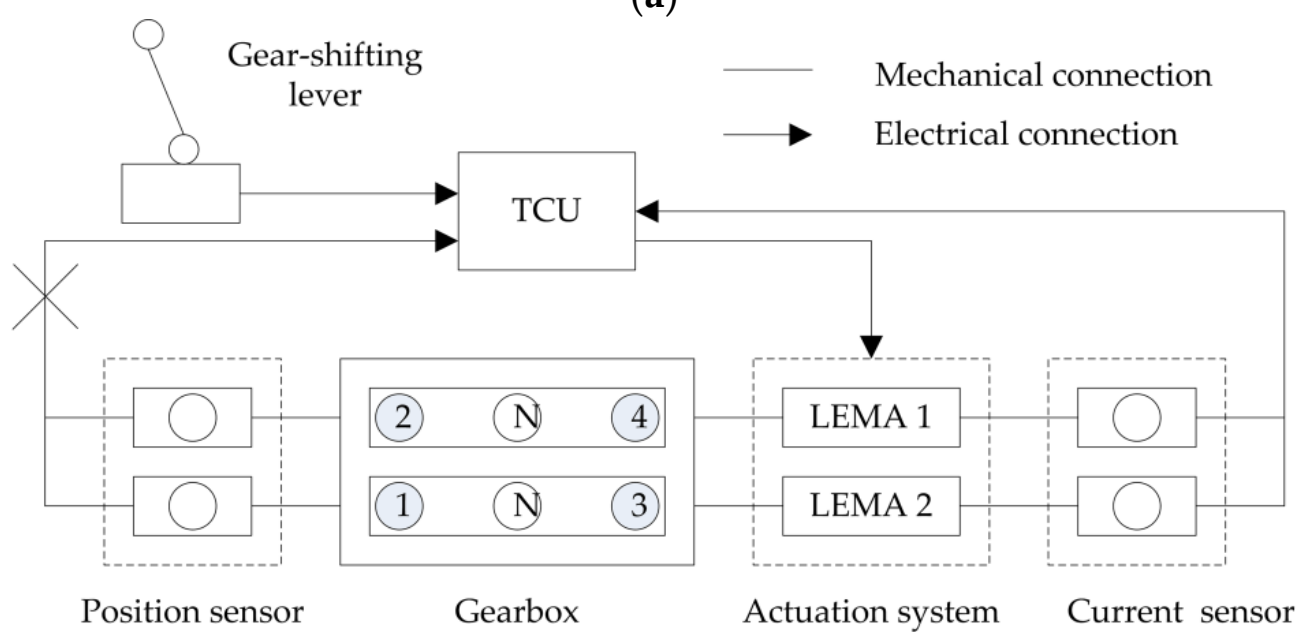

(b)

Figure 1. The independent gear-shifting actuation system: (a) prototype; and (b) schematic diagram. LEMA: linear electromagnetic actuator; TCU: transmission control unit.

The structure and composition of the LEMA is represented schematically in Figure 2. The LEMA basically consists of permanent magnets, a moving coil, outer core, inner core and connecting plate [39]. A tubular structure is applied since it has no end effect and cogging effect. The high energy product sintered $\mathrm{NdFeB}$ magnet $(45 \mathrm{SH})$ is adopted to achieve a high driving force, and a maximum operating temperature of $150^{\circ} \mathrm{C}$ is selected for the automotive application environment. Permanent magnets are mounted on the outer core parts, and the Halbach magnetized topology is used to maximize the driving force of the LEMA. When current is applied to the moving coil, it interacts with the radial 
air-gap magnetic field via Lorentz force principle to create a proportional axial force, whose direction is determined by the polarity of the current-producing voltage, according to Fleming's left-hand rule.

As shown in Figure 3, the LEMA can be modeled mathematically as follows:

$$
\begin{gathered}
I(t)=-\frac{R}{L} I(t)-\frac{k_{e}}{L} v(t)+\frac{1}{L} U(t) \\
S(t)=v(t) \\
v(t)=\frac{k_{e}}{m} I(t)-\frac{c}{m} v(t)-\frac{1}{m} F_{d}
\end{gathered}
$$

where, Equation (1) represents the electrical subsystem of the actuator. $U$ is the applied voltage of the LEMA, $R$ is the resistance of the moving coil, $I$ is the current through the moving coil, $L$ is the inductance of the moving coil. Equations (2) and (3) both describe the mechanical subsystem of the actuator. $S$ is the position of the moving coil, $v$ is the velocity of the moving coil, $c$ is the viscous friction damping coefficient, $F_{d}$ is the total bounded disturbance force applied on the moving coil, $m$ is the mass of the moving part in the gear-shifting mechanism, $k_{e}$ is the actuator coefficient.

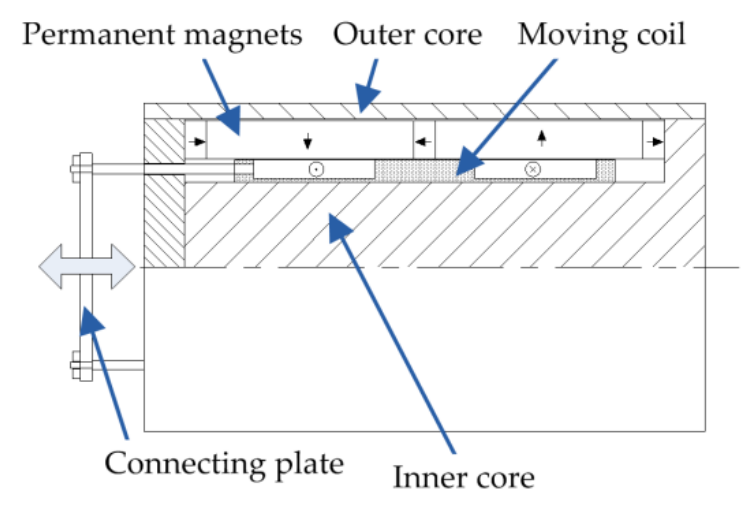

Figure 2. The structure and composition of the LEMA.

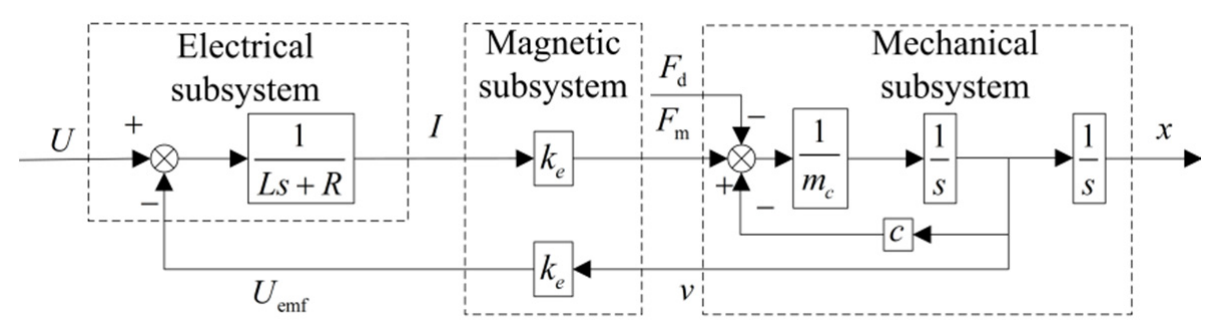

Figure 3. System block diagram of the LEMA.

Define the state vector $x=\left[\begin{array}{lll}x_{1} & x_{2} & x_{3}\end{array}\right]^{\mathrm{T}}=[S, v, I]^{\mathrm{T}}$, then the model of the LEMA can be rewritten in the following standard form:

$$
\left\{\begin{array}{l}
\dot{x}_{1}=x_{2} \\
\dot{x}_{2}=f_{1}\left(x_{1}, x_{2}\right)+r_{1} x_{3}+d_{1} \\
\dot{x}_{3}=f_{2}\left(x_{1}, x_{2}, x_{3}\right)+r_{2} u+d_{2}
\end{array}\right.
$$

where

$$
f_{1}\left(x_{1}, x_{2}\right)=-\frac{c}{m} x_{2}, f_{2}\left(x_{1}, x_{2}, x_{3}\right)=-\frac{k_{e}}{L} x_{2}-\frac{R}{L} x_{3}, r_{1}=\frac{k_{e}}{m}, r_{2}=\frac{1}{L} .
$$


Since $x_{1}$-subsystem is an integral system, there exists no uncertainty. The disturbance $d_{1}$ is determined by the parameter uncertainties and external load forces from the $x_{2}$-subsystem, and the disturbance $d_{2}$ is determined by the parameter uncertainties from the $x_{3}$-subsystem.

\section{Velocity Estimator}

LEMAs use the motor effect to generate force and motion on the moving coil in the magnetic field. Velocity can be estimated by exploiting the generator effect, i.e., a coil moving in a magnetic field generates a back electromotive force that is proportional to velocity. A velocity estimator is built based on Equation (1), and the position is obtained by integrating the high-precision estimated velocity. This method avoids using the complete system model that contains mechanical uncertainties.

When input current is measured, from Equation (1), the velocity can be calculated as follows:

$$
v(t)=\frac{U(t)-I(t) R-L \frac{d I(t)}{d t}}{k_{e}}
$$

The velocity estimation error is defined as $e_{v}(t)=v(t)-\hat{v}(t)$, suppose the change rate of the estimated velocity is proportional to the error between the actual and the estimated velocity, thus a velocity estimator is designed as follows:

$$
\frac{d \hat{v}(t)}{d t}=H[v(t)-\hat{v}(t)]=H e_{v}(t)
$$

where $H$ is the estimator parameter, $v(t)$ is the actual velocity, and $\hat{v}(t)$ is the estimated velocity.

If $H \gg 0$, then the dynamics of the estimated velocity is faster than that of the physical system,

$$
\left\|\frac{d \hat{v}(t)}{d t}\right\| \gg\left\|\frac{d v(t)}{d t}\right\|
$$

Taking the differentiation of $e_{v}(t)$, then

$$
\frac{d e_{v}(t)}{d t}=\frac{d v(t)}{d t}-\frac{d \hat{v}(t)}{d t}
$$

Combining (6) with (8) gives

$$
\frac{d e_{v}(t)}{d t}+H e_{v}(t)=\frac{d v(t)}{d t}
$$

If the following Lyapunov function is considered:

$$
V=\frac{1}{2} e_{v}^{2}(t)
$$

Also considering that

$$
V=e_{v}(t) \dot{e}_{v}(t)
$$

Combining (8) with (11) yields

$$
V=e_{v}(t)\left[\frac{d v(t)}{d t}-\frac{d \hat{v}(t)}{d t}\right]
$$

After inserting (6) into (12), then

$$
V=\frac{1}{H}\left[\frac{d \hat{v}(t)}{d t} \frac{d v(t)}{d t}-\left(\frac{d \hat{v}(t)}{d t}\right)^{2}\right]
$$


If $H \gg 0$, combining (7) with (13), then

$$
V<0
$$

Hence the velocity estimator is asymptotically stable,

$$
\lim _{t \rightarrow+\infty} e_{v}(t)=0
$$

Since the measured current contains noise, the differential process of the current will introduce undesirable spikes. Therefore, the function term containing the derivative of the measured current should be removed from the velocity estimator.

Define the supplementary variable is as follows:

$$
\eta(t)=\hat{v}(t)+N(I(t))=\hat{v}(t)+k_{a} I(t)
$$

where $N(I(t))$ is a function of current, $k_{a}$ is the parameter.

Taking the derivative on both sides of (16), then

$$
\frac{d \eta(t)}{d t}=\frac{d \hat{v}(t)}{d t}+k_{a} \frac{d I(t)}{d t}
$$

Combining (5) and (6) with (17), then

$$
\begin{aligned}
\frac{d \eta(t)}{d t} & =H[v(t)-\hat{v}(t)]+k_{a} \frac{d I(t)}{d t} \\
& =H \frac{U(t)-I(t) R-L \frac{d I(t)}{d t}}{k_{e}}-H \hat{v}(t)+k_{a} \frac{d I(t)}{d t} \\
& =\frac{H}{k_{e}}(U(t)-I(t) R)-H \hat{v}(t)+\left(k_{a}-\frac{H L}{k_{e}}\right) \frac{d I(t)}{d t}
\end{aligned}
$$

Therefore, if only

$$
k_{a}=\frac{H L}{k_{e}}
$$

Then, the velocity estimator can be changed into the expression as follows:

$$
\begin{gathered}
\frac{d \eta(t)}{d t}=\frac{H}{k_{e}}[U(t)-I(t) R]-H \hat{v}(t) \\
\hat{v}(t)=\eta(t)-k_{a} I(t)
\end{gathered}
$$

\section{Model-Assisted Reduced-Order Extended State Observer (ESO) Based Cascade Controller Design}

\subsection{Model-Assisted Reduced-Order ESO}

In this section, the reduced-order ESO is designed to estimate the lumped disturbances in $x_{2}$-subsystem and $x_{3}$-subsystem. Since $x_{2}$ and $x_{3}$ are available, based on the method in [33], specified reduced-order ESO is given as follows:

$$
\begin{gathered}
\left\{\begin{array}{l}
\dot{z}_{2}=-\beta_{1} z_{2}-\beta_{1}^{2} x_{2}-\beta_{1} r_{1} x_{3} \\
\hat{d}_{1}=z_{2}+\beta_{1} x_{2}, \beta_{1}>0
\end{array}\right. \\
\left\{\begin{array}{l}
\dot{z}_{3}=-\beta_{2} z_{3}-\beta_{2}^{2} x_{3}-\beta_{2} r_{2} u \\
\hat{d}_{2}=z_{3}+\beta_{2} x_{3}, \beta_{2}>0
\end{array}\right.
\end{gathered}
$$

where $\hat{d}_{1}$ is the estimate of the lumped uncertainties (the sum term of $f_{1}\left(x_{1}, x_{2}\right)$ and $d_{1}$ ) in the $x_{2}$-subsystem, $\hat{d}_{2}$ is the estimate of the lumped uncertainties (the sum term of $f_{2}\left(x_{1}, x_{2}, x_{3}\right)$ and $d_{2}$ ) in the $x_{3}$-subsystem, $z_{2}$ and $z_{3}$ are the auxiliary state of the observer, $\beta_{1}$ and $\beta_{2}$ are the observer gain. 
Note that the internal dynamics $f_{1}\left(x_{1}, x_{2}\right)$ and $f_{2}\left(x_{1}, x_{2}, x_{3}\right)$ are available, to reduce the estimate burden of the observer, with this given model information, the model-assisted reduced-order ESO is proposed as follows:

$$
\begin{gathered}
\left\{\begin{array}{l}
\dot{z}_{2}=-\beta_{1} z_{2}-\beta_{1}^{2} x_{2}-\beta_{1}\left[f_{1}\left(x_{1}, x_{2}\right)+r_{1} x_{3}\right] \\
\hat{d}_{1}=z_{2}+\beta_{1} x_{2}, \beta_{1}>0
\end{array}\right. \\
\left\{\begin{array}{l}
\dot{z}_{3}=-\beta_{2} z_{3}-\beta_{2}^{2} x_{3}-\beta_{2}\left[f_{2}\left(x_{1}, x_{2}, x_{3}\right)+r_{2} u\right] \\
\hat{d}_{2}=z_{3}+\beta_{2} x_{3}, \beta_{2}>0
\end{array}\right.
\end{gathered}
$$

where $\hat{d}_{1}$ is the estimate of the lumped uncertainty $d_{1}$ in the $x_{2}$-subsystem, $\hat{d}_{2}$ is the estimate of the lumped uncertainty $d_{2}$ in the $x_{3}$-subsystem.

Based on (3) and (24), the error dynamics of disturbance estimate for $x_{2}$-subsystem can be derived as follows:

$$
\begin{aligned}
\dot{e}_{o 1} & =\dot{d}_{1}-\dot{\hat{d}}_{1}=\dot{d}_{1}-\left(\dot{z}_{2}+\beta_{1} \dot{x}_{2}\right) \\
& =\dot{d}_{1}+\beta_{1} z_{2}+\beta_{1}^{2} x_{2}+\beta_{1}\left[f_{1}\left(x_{1}, x_{2}\right)+r_{1} x_{3}\right]-\beta_{1}\left[f_{1}\left(x_{1}, x_{2}\right)+r_{1} x_{3}+d_{1}\right] \\
& =\dot{d}_{1}+\beta_{1}\left(z_{2}+\beta_{1} x_{2}\right)-\beta_{1} d_{1} \\
& =\dot{d}_{1}+\beta_{1}\left(\hat{d}_{1}-d_{1}\right) \\
& =-\beta_{1} e_{o 1}+\dot{d}_{1}
\end{aligned}
$$

Using the same derivation process, the error dynamics of disturbance estimate for $x_{3}$-subsystem can be derived as follows:

$$
\dot{e}_{02}=-\beta_{2} e_{02}+\dot{d}_{2}
$$

Together with (26) and (27), the overall error dynamics of disturbance estimate for the LEMA system can be described in the following compact form:

$$
\dot{\mathrm{E}}_{o}=A_{o} E_{o}+\dot{\boldsymbol{d}}_{o}
$$

where

$$
\boldsymbol{E}_{o}=\left[\begin{array}{ll}
e_{01} & e_{02}
\end{array}\right]^{\mathrm{T}}=\left[\begin{array}{ll}
d_{1}-\hat{d}_{1} & d_{2}-\hat{d}_{2}
\end{array}\right]^{\mathrm{T}}, \boldsymbol{d}_{o}=\left[\begin{array}{ll}
\dot{d}_{1} & \dot{d}_{2}
\end{array}\right]^{\mathrm{T}}, \boldsymbol{A}_{o}=\operatorname{diag}\left\{\begin{array}{ll}
-\beta_{1} & -\beta_{2}
\end{array}\right\}
$$

Suppose the eigenvalues of the matrix $A_{o}$ have negative real parts, i.e., the matrix $A_{o}$ is a Hurwitz matrix, so there exists a symmetric positive definite matrix $\boldsymbol{P}$ and $Q$, such that

$$
\boldsymbol{A}_{o}^{T} \boldsymbol{P}+\boldsymbol{P} A_{o}=-\boldsymbol{Q}
$$

Let $\min \left(\left|\beta_{i}\right|\right), i=1,2$ denote the smallest eigenvalue of $\boldsymbol{A}_{\boldsymbol{o}}$. Define a Lyapunov function as follows:

$$
V_{o}=\frac{1}{2} E_{o}^{\mathrm{T}} \boldsymbol{P} E_{o}
$$

Then, differentiating it along the trajectory of (29) yields:

$$
\begin{aligned}
\dot{V}_{o} & =\frac{1}{2} \boldsymbol{E}_{o}^{\mathrm{T}}\left(\boldsymbol{A}_{o}^{\mathrm{T}} \boldsymbol{P}+\boldsymbol{P} \boldsymbol{A}_{o}\right) \boldsymbol{E}_{o}+\boldsymbol{E}_{o}^{\mathrm{T}} \boldsymbol{P} \dot{\boldsymbol{d}}_{o} \\
& \leq-\frac{1}{2} \boldsymbol{E}_{o}^{\mathrm{T}} \boldsymbol{Q} \boldsymbol{E}_{o}+\left\|\boldsymbol{E}_{o}\right\|\|\boldsymbol{P}\|\left\|\dot{\boldsymbol{d}}_{o}\right\| \\
& \leq-\frac{1}{2}\left\|\boldsymbol{E}_{o}\right\|^{2} \boldsymbol{Q}+\left\|\boldsymbol{E}_{o}\right\|\|\boldsymbol{P}\| \max \left(\bar{d}_{i}\right) \\
& \leq-\left\|\boldsymbol{E}_{o}\right\|^{2}\|\boldsymbol{P}\| \min \left(\left|\beta_{i}\right|\right)+\left\|\boldsymbol{E}_{o}\right\|\|\boldsymbol{P}\| \max \left(\bar{d}_{i}\right) \\
& \leq-\left\|\boldsymbol{E}_{o}\right\|\left(\left\|\boldsymbol{E}_{o}\right\|\|\boldsymbol{P}\| \min \left(\left|\beta_{i}\right|\right)-\|\boldsymbol{P}\| \max \left(\bar{d}_{i}\right)\right)
\end{aligned}
$$


Therefore, by selecting the appropriate large observer gain, the estimate error convergence, and the norm of the estimate error is bounded by

$$
\left\|E_{o}\right\| \leq \frac{\max \left(\bar{d}_{i}\right)}{\min \left(\left|\beta_{i}\right|\right)}, i=1,2
$$

\subsection{Cascade Feedback Control Law Design}

\subsubsection{Feedback Control Law for the Position Loop}

In this section, the aim is to design a feedback control law for the position loop to track the reference command. As shown in Figure 4, the desired reference trajectory for position control is generated by a second-order transfer function. The mathematical expression is as follows:

$$
\left\{\begin{array}{l}
\dot{S}_{d}=v_{d} \\
\dot{v}_{d}=a_{d} \\
a_{d}=-\omega_{n}{ }^{2} S_{d}-2 \xi \omega_{n} v_{d}+\omega_{n}{ }^{2} r
\end{array}\right.
$$

where $\xi$ and $\omega_{n}$ is the desired damping ratio and system bandwidth, $r$ is the target position, which is a step function.

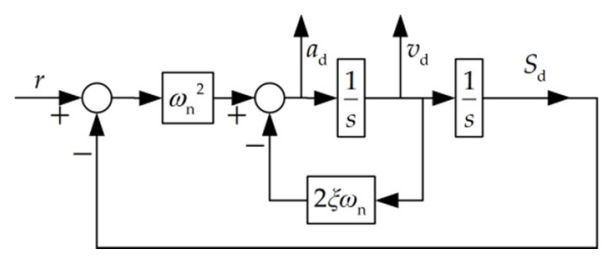

Figure 4. Second-order dynamic system for reference trajectory generation.

Desired damping ratio $\xi$ and system bandwidth $\omega_{n}$ should be reasonably chosen with respect to both the system dynamics and the constraints of the input $u$. For a given input signal $r$, the reference signal is generated on line, and $S_{d}, v_{d}$ and $a_{d}$ are the desired position, velocity and acceleration, respectively.

The tracking error between the actual and the reference signal is defined as $e_{p}=S-S_{d}$, then the following expression can be obtained:

$$
\begin{aligned}
& v=\dot{S}=\dot{e}_{p}+\dot{S}_{d}=\dot{e}_{p}+v_{d} \\
& a=\ddot{S}=\ddot{e}_{p}+\ddot{S}_{d}=\ddot{e}_{p}+a_{d}
\end{aligned}
$$

Considering the model of mechanical subsystems in the following form:

$$
\ddot{S}=-\frac{c}{m} v+\frac{k_{e}}{m} I+d_{1}
$$

Inserting Equations (34) and (35) into (36) yields

$$
\ddot{e}_{p}+a_{d}=-\frac{c}{m}\left(\dot{e}_{p}+v_{d}\right)+\frac{k_{e}}{m} I+d_{1}
$$

Due to the effect of the model-assisted reduced-order ESO, nonlinear uncertainties and disturbances that exist in the mechanical subsystem can be compensated, so the new system dynamic can be approximated as a linear system. Therefore, two proportion structures are adopted as the feedback control law. One of them uses the difference between the desired and actual position, and the 
other one uses the difference between the desired and actual velocity. The overall control law for the mechanical subsystem is as follows:

$$
I_{v}=\frac{m}{k_{e}}\left(a_{d}+\frac{c}{m} v_{d}-h_{1} e_{p}-h_{2} \dot{e}_{p}-\hat{d}_{1}\right)
$$

where $h_{1}$ and $h_{2}$ are proportion parameters.

Insert Equation (38) into (37), the error dynamics of the position loop system is given by:

$$
\ddot{e}_{p}+\left(\frac{c}{m}+h_{2}\right) \dot{e}_{p}+h_{1} e_{p}=e_{o 1}
$$

Considering (32), then

$$
\ddot{e}_{p}+\left(\frac{c}{m}+h_{2}\right) \dot{e}_{p}+h_{1} e_{p}=0
$$

In order to guarantee the stability of the system, the formula $s^{2}+\left(\frac{c}{m}+h_{2}\right) s+h_{1}$ should be a Hurwitz polynomial. To simplify the tuning process, it can be set as

$$
\left(s+\omega_{c}\right)^{2}=0, \omega_{c}>0
$$

Thus,

$$
\begin{gathered}
h_{1}=\omega_{c}^{2} \\
h_{2}=2 \omega_{c}-\frac{c}{m}
\end{gathered}
$$

where $k$ is the only parameter to be tuned.

\subsubsection{Feedback Control Law for the Current Loop}

In this section, the aim is to design a feedback control law for the current loop to track the desired current $I_{v}$, which is the output of the position loop.

The desired current $\eta_{1}$ and its derivative $\eta_{2}$ are obtained through the following tracking differentiator:

$$
\left\{\begin{array}{l}
\dot{\eta}_{1}=\eta_{2} \\
\dot{\eta}_{2}=\tau^{2}\left(I_{v}-\eta_{1}\right)-2 \tau \eta_{2}
\end{array}\right.
$$

where $\eta_{1}$ is the estimate of $I_{v}, \eta_{2}$ is the estimate of $\dot{I}_{v}$.

The change rate of current dynamics is designed as

$$
\dot{I}_{d}=\eta_{2}+\beta\left(\eta_{1}-I\right), \beta>0
$$

With the estimate $\hat{d}_{2}$, inserting (45) into the following electrical subsystem (46)

$$
\dot{x}_{3}=f_{2}\left(x_{1}, x_{2}, x_{3}\right)+r_{2} u+d_{2}
$$

So the designed current control law is as follows:

$$
u=r_{2}^{-1}\left[\eta_{2}+\beta\left(\eta_{1}-x_{3}\right)-f_{2}\left(x_{1}, x_{2}, x_{3}\right)-\hat{d}_{2}\right]
$$

where $\beta$ is a proportion parameter.

Define the tracking error $e_{I}=x_{3}-\eta_{1}$, then taking the derivative yields

$$
\begin{aligned}
\dot{e}_{I} & =\dot{x}_{3}-\dot{\eta}_{1} \\
& =f_{2}\left(x_{1}, x_{2}, x_{3}\right)+r_{2} r_{2}^{-1}\left[\eta_{2}+\beta\left(\eta_{1}-x_{3}\right)-f_{2}\left(x_{1}, x_{2}, x_{3}\right)-\hat{d}_{2}\right]+d_{2}-\eta_{2} \\
& =\beta\left(\eta_{1}-x_{3}\right)+d_{2}-\hat{d}_{2} \\
& =-\beta e_{I}+e_{o 2}
\end{aligned}
$$


Define the Lyapunov function as follows:

$$
V_{I}=\frac{1}{2} e_{I}^{2}
$$

Taking the derivative of $V_{I}$ along the trajectory of (48) yields

$$
\begin{aligned}
\dot{V}_{I} & =e_{I} \dot{e}_{I} \\
& =-e_{I}\left(\beta e_{I}-e_{o 2}\right)
\end{aligned}
$$

Therefore, within finite time, the tracking error is bounded by:

$$
\left\|e_{I}\right\| \leq \frac{\left\|e_{02}\right\|}{\beta}
$$

According to (32), the error $e_{02}$ is bounded, so the closed-loop electrical subsystem is asymptotically stable.

In conclusion, Figure 5 provides a conceptual block diagram of the whole control algorithm.

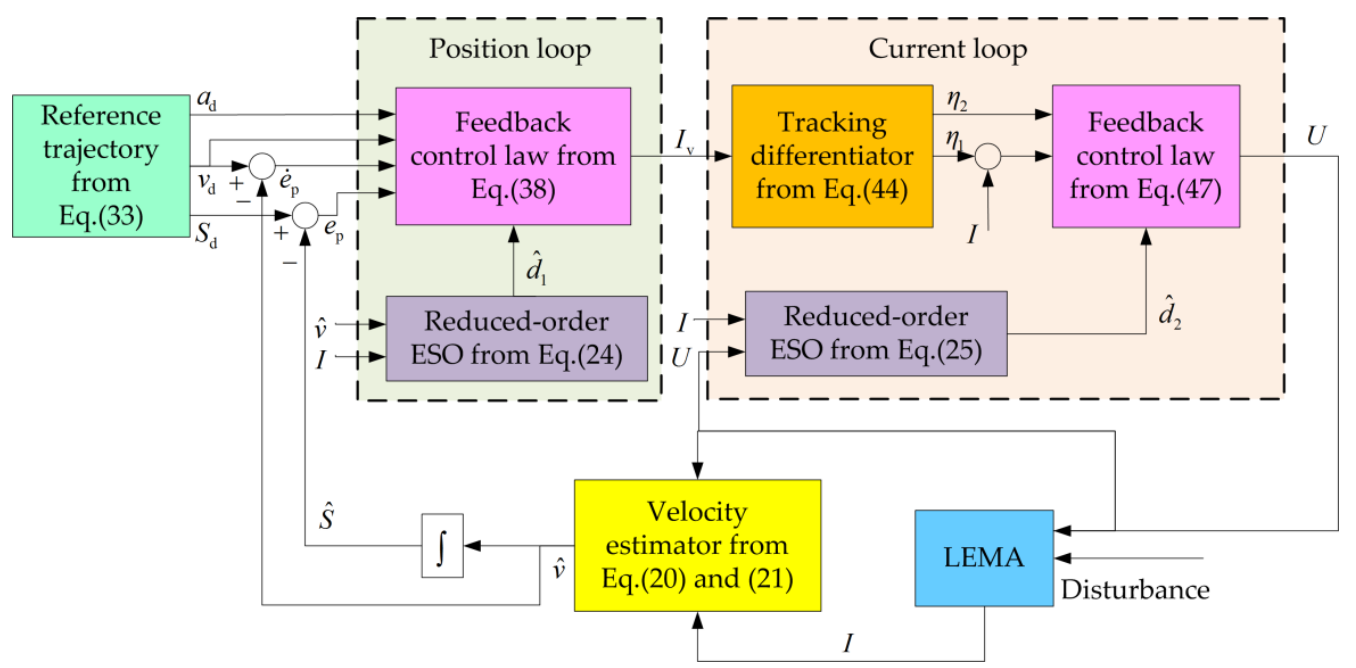

Figure 5. Block diagram of the whole control algorithm.

The discrete realization of the velocity estimator and controller using the forward Euler method are listed below.

Taking the velocity estimator from Equations (20) and (21), and integrating the high-precision estimated velocity to obtain the position:

$$
\left\{\begin{array}{l}
\eta(k)=\left(1+h_{s} H\right)^{-1}\left[\eta(k-1)+h_{s} \frac{H}{k_{e}}[U(k)-I(k) R]+h_{s} \frac{H^{2} L}{k_{e}} I(k)\right] \\
\hat{v}(k)=\eta(k)-\frac{H L}{k_{e}} I(k) \\
\hat{S}(k)=\sum_{0}^{k} \hat{v}(k)
\end{array}\right.
$$

Reduced-order ESO from Equations (24) and (25):

$$
\begin{gathered}
\left\{\begin{array}{l}
z_{2}(k+1)=z_{2}(k)+h_{s}\left\{-\beta_{1} z_{2}(k)-\beta_{1}^{2} x_{2}(k)-\beta_{1}\left[f_{1}\left(x_{1}(k), x_{2}(k)\right)+r_{1} x_{3}(k)\right]\right\} \\
\hat{d}_{1}(k)=z_{2}(k)+\beta_{1} x_{2}(k), \beta_{1}>0
\end{array}\right. \\
\left\{\begin{array}{l}
z_{3}(k+1)=z_{3}(k)+h_{s}\left\{-\beta_{2} z_{3}(k)-\beta_{2}^{2} x_{3}(k)-\beta_{2}\left[f_{2}\left(x_{1}(k), x_{2}(k), x_{3}(k)\right)+r_{2} u(k)\right]\right\} \\
\hat{d}_{2}(k)=z_{3}(k)+\beta_{2} x_{3}(k), \beta_{2}>0
\end{array}\right.
\end{gathered}
$$


Reference trajectory from Equation (33):

$$
\left\{\begin{array}{l}
S_{d}(k+1)=S_{d}(k)+h_{s} v_{d}(k) \\
v_{d}(k+1)=v_{d}(k)+h_{s} a_{d}(k) \\
a_{d}(k)=-\omega_{n}{ }^{2} S_{d}(k)-2 \xi \omega_{n} v_{d}(k)+\omega_{n}{ }^{2} r
\end{array}\right.
$$

Feedback control law from Equation (38):

$$
I_{v}(k+1)=\frac{m}{k_{e}}\left\{a_{d}(k+1)+\frac{c}{m} v_{d}(k+1)-h_{1}\left[\hat{S}(k)-S_{d}(k)\right]-h_{2}\left[\hat{v}(k)-v_{d}(k)\right]-\hat{d}_{1}(k)\right\}
$$

Tracking differentiator from Equation (44):

$$
\left\{\begin{array}{l}
\eta_{1}(k+1)=\eta_{1}(k)+h_{s} \eta_{2}(k) \\
\eta_{2}(k+1)=\eta_{2}(k)+h_{s}\left\{\tau^{2}\left[I_{v}(k)-\eta_{1}(k)\right]-2 \tau \eta_{2}(k)\right\}
\end{array}\right.
$$

Feedback control law from Equation (47):

$$
\left.u(k+1)=r_{2}^{-1}\left\{\eta_{2}(k+1)+\beta\left[\eta_{1}(k+1)-x_{3}(k+1)\right]-f_{2}\left(x_{1}(k+1), x_{2}(k+1), x_{3}(k+1)\right)-\hat{d}_{2}(k)\right]\right\}
$$

where $h_{s}$ is the sampling time, $k=1,2, \ldots, n \in N$.

\section{Simulations and Experimental Results}

\subsection{Comparative Simulations}

To validate the effectiveness of the proposed discrete control strategy in Section 4, comparative simulations were implemented on the LEMA with the prototype parameters given in Table 1 by MATLAB/Simulink. The sampling frequency is set to $10 \mathrm{kHz}$.

First, in order to verify the control effect of the current loop, the target current was set as $I_{v}=5 \sin (100 \pi t)$. Due to the influence of temperature variation, the coil resistance $R$ may be different from the nominal values. Here, suppose that the actual resistance of the LEMA has a random error of $\pm 20 \%$ compared to the nominal one. To highlight the importance of the reduced-order ESO, the controllers with and without the reduced-order ESO are tested. As shown in Figure 6, the simulation results demonstrate that the control law of the current loop is effective, and the reduced-order ESO based controller can effectively restrain the influence of parameter variations in the current subsystem. Figure $6 \mathrm{~d}$ shows the tracking error of three control cases. Under nominal model conditions, the maximum tracking error is about $5 \%$. With the help of the reduced-order ESO, the maximum tracking error can still be controlled to around $5 \%$ in the case of parameter changes, but without the reduced-order ESO, the maximum tracking error can only be controlled to $15 \%$ in the case of parameter changes. Therefore, the proposed current loop controller that is based on reduced-order ESO, is insensitive to the parameter variation in the electrical subsystem.

Table 1. Main parameters of the linear electromagnetic actuators (LEMA).

\begin{tabular}{cccc}
\hline Parameter & Symbol & Value & Unit \\
\hline Moving mass & $m$ & 0.15 & $\mathrm{~kg}$ \\
Active stroke & - & 18 & $\mathrm{~mm}$ \\
Resistance & $R$ & 0.68 & $\Omega$ \\
Inductance & $L$ & 0.89 & $\mathrm{mH}$ \\
Actuator coefficient & $k_{e}$ & 15.8 & $\mathrm{~N} / \mathrm{A}$ \\
\hline
\end{tabular}




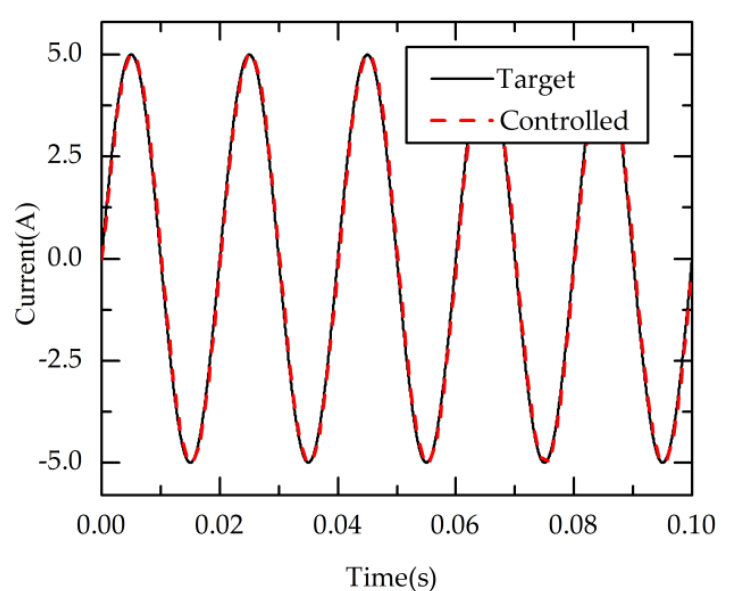

(a)

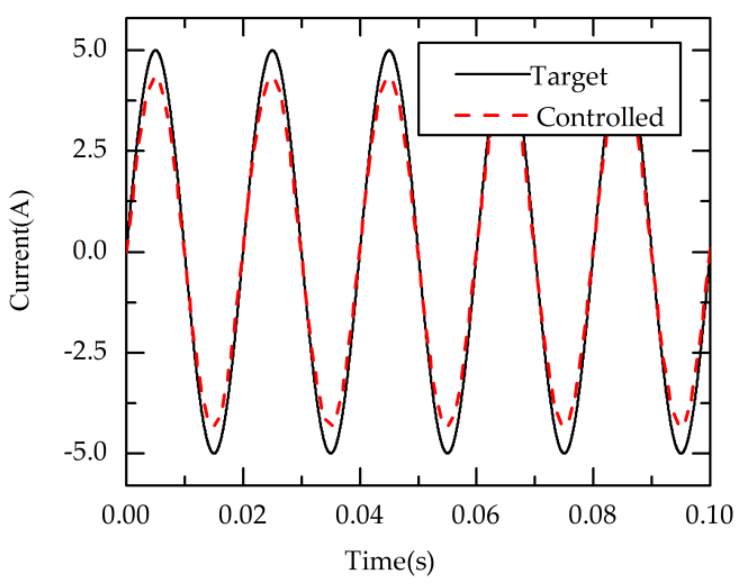

(c)

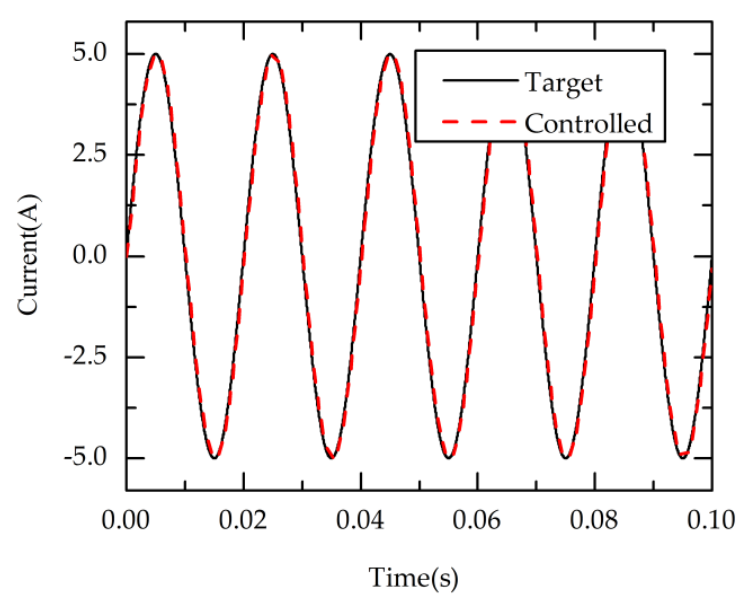

(b)

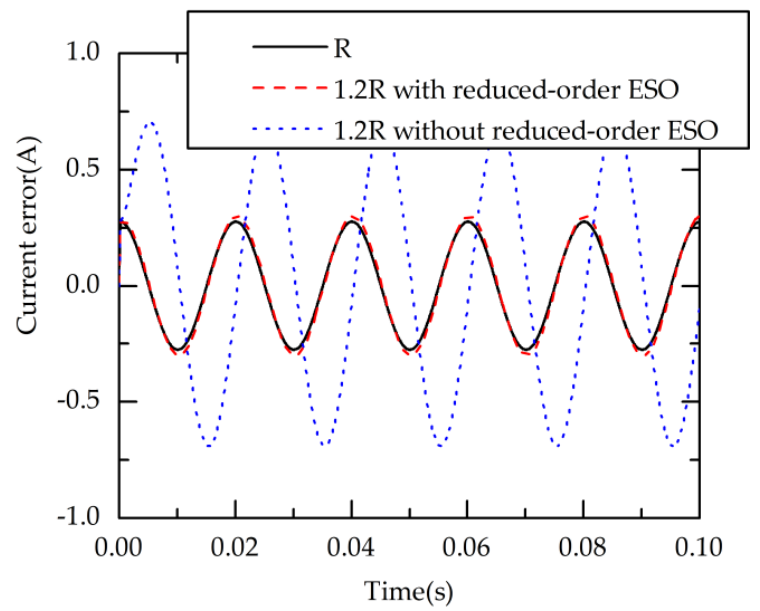

(d)

Figure 6. Simulation results of the current loop: (a) $R$ equals the nominal value, controller with reduced-order extended state observer (ESO); (b) $R$ is $20 \%$ higher than the nominal value, controller with reduced-order ESO; (c) $R$ is $20 \%$ higher than the nominal value, controller without reduced-order ESO; and (d) Current tracking error.

Next, in order to verify the control effect of the position loop, the target position is set as $9 \mathrm{~mm}$. Figure 7 shows the position simulation results of the proposed controller with the same parameter, $\omega_{n}=300$ and the different parameter $\omega_{c}$, and Figure 8 shows the results with the same parameter $\omega_{c}=100$ and the different parameter $\omega_{n}$. Note that the settling time of the position mainly depends on the parameter $\omega_{n}$, and the margin of position error mainly depends on the parameter $\omega_{c}$. Furthermore, the settling time and the margin of position error for the position control are almost unrelated, and can be designed independently.

The controller with the model-assisted reduced-order ESO and that with the reduced-order ESO are compared, and the results of the position error are shown in Figure 9. Note that, with the help of the known model, the margin of position error is significantly reduced, and the convergence speed of position error is increased. 


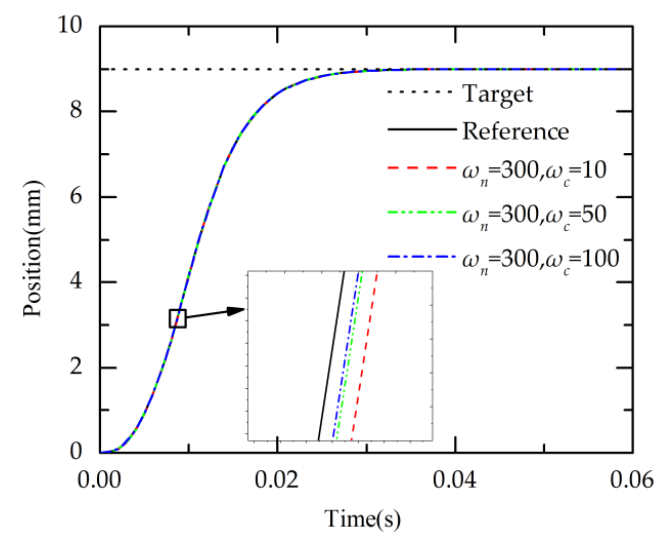

(a)

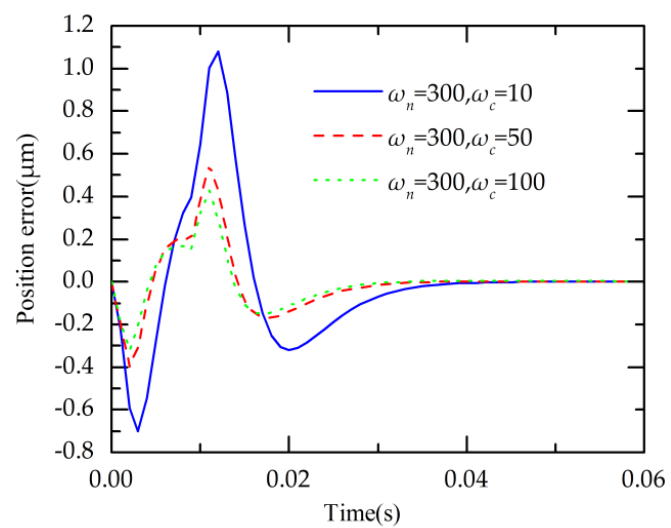

(b)

Figure 7. Simulation results of the proposed controller with the different parameter $\omega_{\mathcal{c}}$, when the parameter $\omega_{n}=300$ : (a) Position; and (b) Position error.

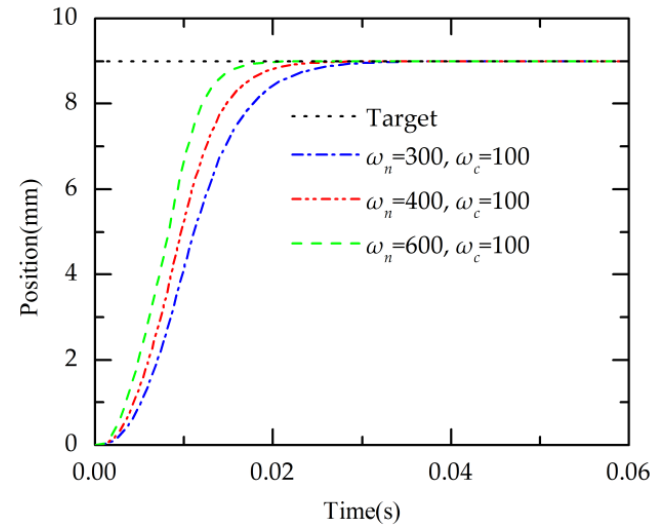

(a)

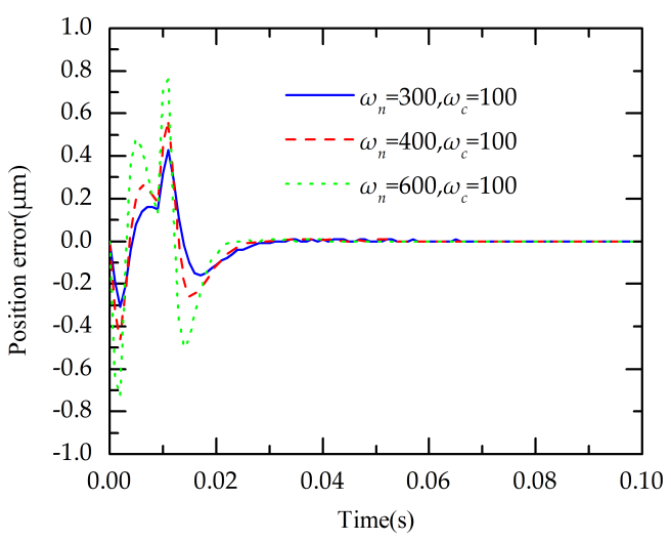

(b)

Figure 8. Simulation results of the proposed controller with the different parameter $\omega_{n}$, when the parameter $\omega_{c}=100$ : (a) Position; and (b) Position error.

To consider the effects of parameter uncertainties on the controller performance, suppose that the model parameters of the LEMA have the random error, which is described as follows:

$$
\left\{\begin{array}{l}
R=R_{0}+0.2 R_{0} \lambda \\
L=L_{0}+0.02 L_{0} \lambda \\
k_{e}=k_{e 0}+0.1 k_{e 0} \lambda \\
m=m_{0}+0.02 m_{0} \lambda \\
c=c_{0}+0.2 c_{0} \lambda
\end{array}\right.
$$

where $R_{0}, L_{0}, k_{e 0}, m_{0}, c_{0}$ are the nominal values of corresponding parameters, and $\lambda \in\left[\begin{array}{ll}-1 & 1\end{array}\right]$ is normally distributed random function.

Figure 10 shows the robustness of the controller when the model parameters have random uncertainties. It can be seen that the errors of the proposed controller in the two cases are both negligible, and the errors converge to zero.

To verify both the parameter uncertainties and the external load force rejection performance, which due to the actual shifting force is difficult to define, different step load force is applied on the actuator at $t=25 \mathrm{~ms}$ and removed at $t=30 \mathrm{~ms}$. As shown in Figure 11, the position curve of the proposed controller can return to the original balance state when the load force is increased to $200 \mathrm{~N}$, 
and the maximum dynamic error is less than $7.8 \%$. Therefore, the proposed controller is robust to the variations of the parameters and external load forces.

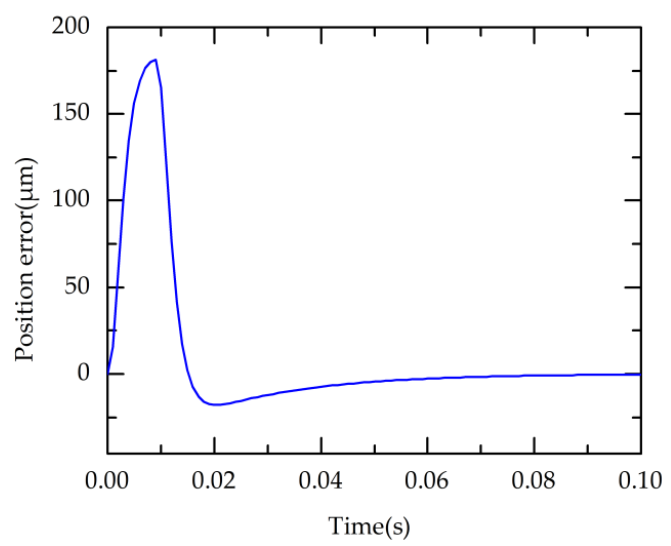

(a)

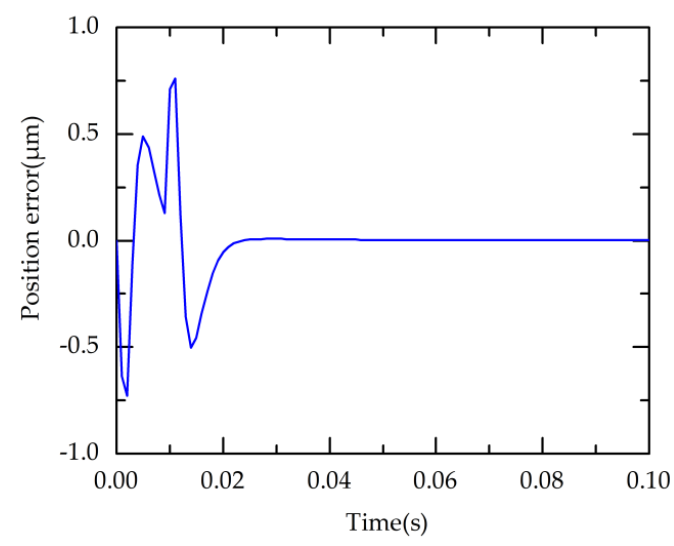

(b)

Figure 9. Position error of the proposed controller: (a) with the reduced-order ESO; and (b) with the model-assisted reduced-order ESO.

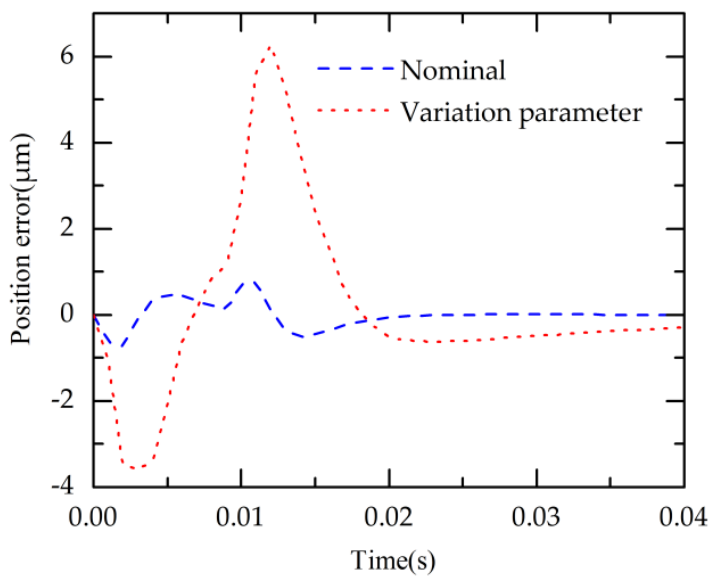

Figure 10. Simulation results of the proposed controller with random parameter variation.

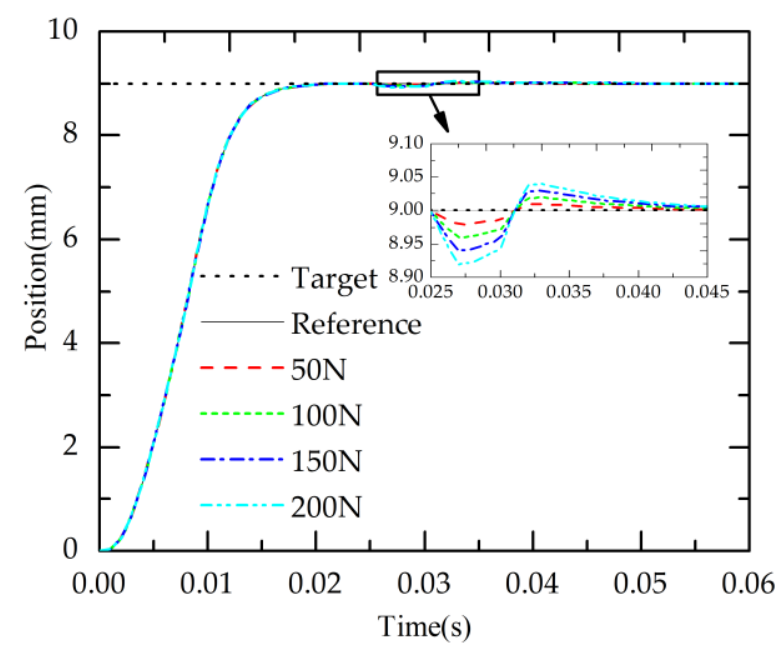

Figure 11. Simulation results of the proposed controller with random parameter variation and external disturbance. 


\subsection{Experimental Results}

In order to validate the effectiveness of the proposed velocity estimator and control method in practice, a gear-shifting test bench was developed. Figure 12 shows the layout and the main components of the experimental set up. It mainly consists of an induction motor, transmission, actuator, sensors, controller and other support mechanisms. Figure 13 shows the structure of the control system. The position of the actuator is monitored by a high-accuracy position sensor (KTM-25 mm). The current through the moving coil is measured with a closed-loop Hall-effect current sensor (TBC20SY). The actuator is controlled by an IGBT H-bridge drive. TMS320F2812 Digital Signal Processor (DSP) with a clock frequency of $150 \mathrm{MHz}$ is applied as the main controller. Sensor signals are transmitted to $\mathrm{A} / \mathrm{D}$ ports after being processed by interface circuits. The sampling frequency of the DSP is set to $10 \mathrm{kHz}$, the switching frequency of the Pulse Width Modulation (PWM) inverter is set to $30 \mathrm{kHz}$. Experimental data is transmitted to the personal computer via an Ethernet cable for display and analysis.

Taking the gear-shifting disengaging phase that only needs position control as an example, the initial position is limited by the synchronizer and actuator, and can be considered as zero. The target position is $9 \mathrm{~mm}$, and the settling time of the reference position is set as around $20 \mathrm{~ms}$. In this phase, the sleeve of the synchronizer should be controlled to the target neutral position precisely within the desired settling time. Figure 14a shows the test results of the position with the proposed controller, and the position sensor is used in the position loop to provide a feedback signal. It can be seen that the controlled position track the reference trajectory with a small delay, this is because the computing power of the fixed-point TMS320F2812 DSP and the measurement accuracy of the sensors are limited. Similarly, the estimated position also lags behind the measured value. The derivative of the measured position and the estimated velocity is shown in Figure 14b. It is quite obvious that the derivative of the measured position is affected by the measurement noise, but the velocity estimator can observe the velocity effectively and removes undesirable spikes existing in the velocity observation.

Next, the velocity estimator replaces the position sensor in the control system, i.e., the measurement of the position sensor is just used for comparison. As shown in Figure 15, the test results display a small overshoot of $2.2 \%$ due to the effect of the velocity estimate. As stated in Taguchi et al. [10], this overshoot can be accepted and will not affect the gear-shifting performance. Therefore, the sensorless control of an independent gear-shifting actuation system with the model-assisted reduced-order ESO based cascade controller is technically feasible.

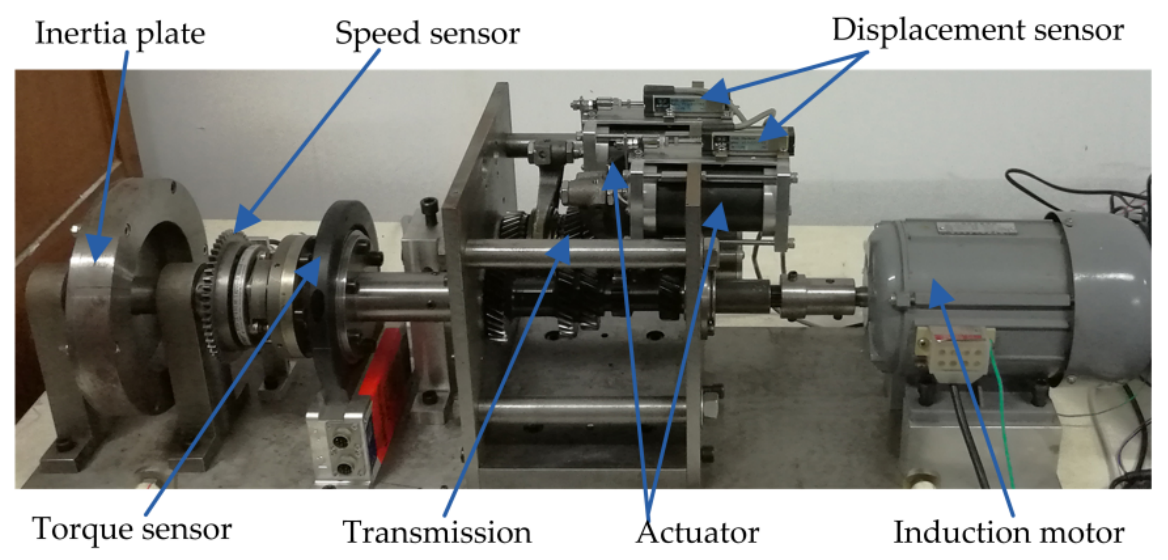

Figure 12. The experimental set up. 


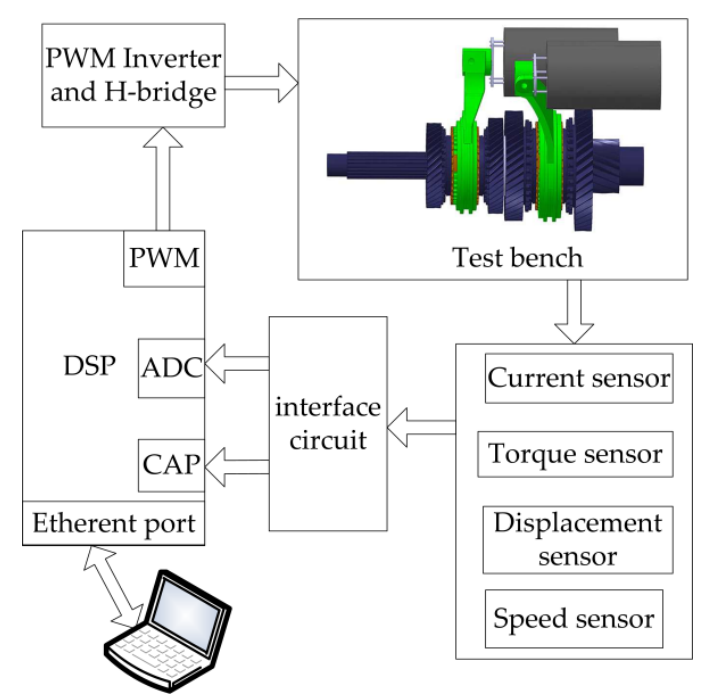

Figure 13. The structure of the control system. ADC: Analog to Digital Converter; CAP: Capture Unit.

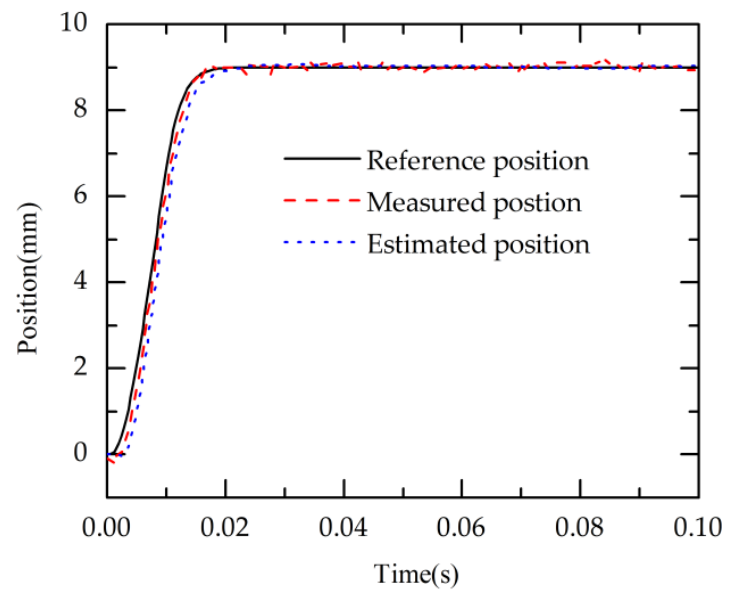

(a)

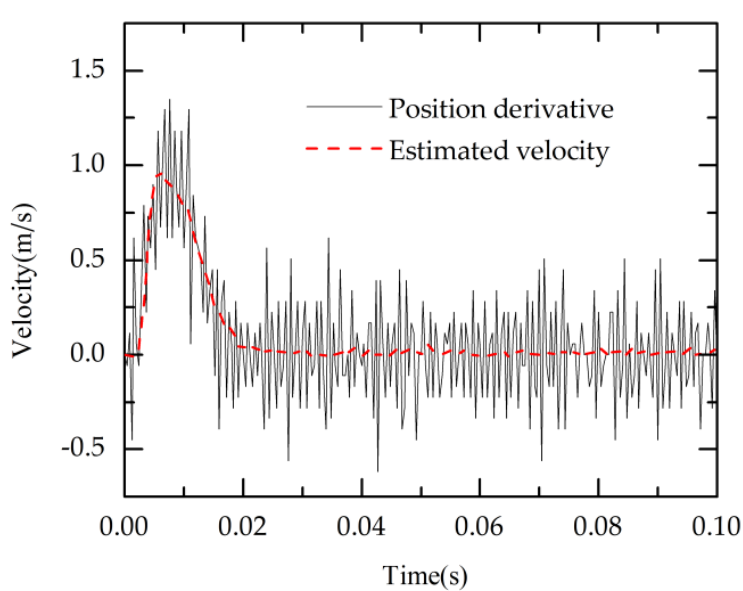

(b)

Figure 14. Experimental results for the control system using a position sensor: (a) Position; and (b) Velocity.

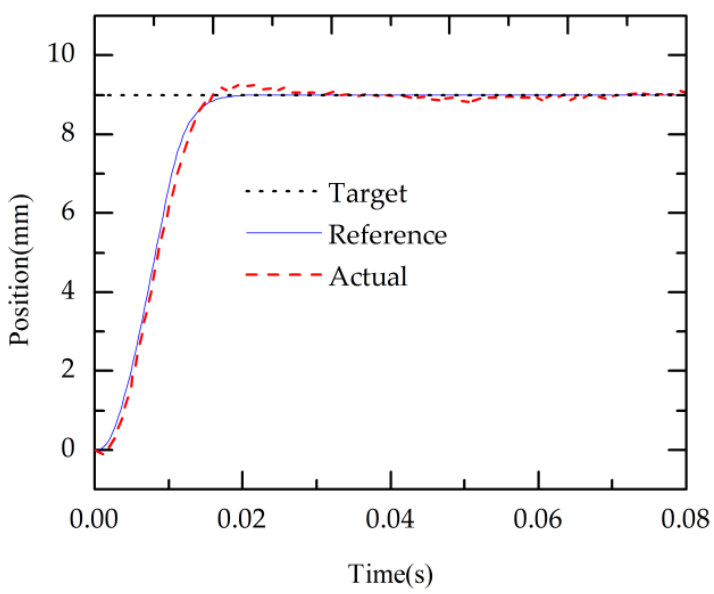

Figure 15. Experimental results for the control system using a velocity estimator. 


\section{Conclusions}

In order to minimize the shifting duration of AMT, the position control of independent gear-shifting systems that are based on LEMAs, is a crucial task. In this paper, the main conclusions are as follows:

1. A velocity estimator based on a sensorless control method is designed. With the measurements of input current, velocity is estimated through the electrical subsystem, and the complete system model with mechanical uncertainties is avoided.

2. With partially known model information, the model-assisted reduced-order ESOs are constructed to estimate and compensate for the uncertainties in the velocity and the current loop. The simulation results indicate that the settling time and the margin of position error for the position control can be regulated separately, and the proposed controller is robust to the variations of the parameters and external load forces.

3. The bench experimental results show that the proposed controller with the position sensor has better performance, but the controller using a velocity estimator can also complete the gear-change process with acceptable performance. The sensorless control of the independent gear-shifting system is technically feasible. Sensorless control avoids bulky and complicated measurement systems, so it is very promising for real world application. This provides a new approach for the development of the AMT shifting system.

Acknowledgments: This work was supported by the National Natural Science Foundation of China (Grant No. 51505263); and the Natural Science Foundation of Jiangsu Province, China (Grant No. BK20130762).

Author Contributions: Yingchao Zhou and Siqin Chang proposed the idea, designed the schemes of simulations and experiments. Yingchao Zhou implemented it by simulations and experiments and wrote the manuscript. Siqin Chang made suggestions in the manuscript correction and improvements.

Conflicts of Interest: The authors declare no conflict of interest.

\section{References}

1. Chang, S. Automotive Powertrain, 2nd ed.; China Machine Press: Beijing, China, 2016; ISBN 978-7-111-51625-5.

2. Glielmo, L.; Iannelli, L.; Vacca, V.; Vasca, F. Gearshift control for automated manual transmission. IEEE/ASME Trans. Mechatron. 2006, 11, 17-26. [CrossRef]

3. Lu, T.; Dai, F.; Zhang, J.; Wu, M. Optimal control of dry clutch engagement based on the driver's starting intentions. Proc. Inst. Mech. Eng. Part D J. Automob. Eng. 2012, 226, 1048-1057. [CrossRef]

4. Pettersson, M.; Nielsen, L. Gear shifting by engine control. IEEE Trans. Control Syst. Technol. 2000, 8, 495-507. [CrossRef]

5. Lucente, G.; Montanari, M.; Rossi, C. Modelling of an automated manual transmission system. Mechatronics 2007, 17, 73-91. [CrossRef]

6. Balau, A.E.; Caruntu, C.F.; Lazar, C. Simulation and control of an electro-hydraulic actuated clutch. Mech. Syst. Sig. Process 2011, 25, 1911-1922. [CrossRef]

7. Grancharova, A.; Johansen, T. Design and comparison of explicit model predictive controllers for an electropneumatic clutch actuator using on/off valves. IEEE/ASME Trans. Mechatron. 2011, 16, 665-673. [CrossRef]

8. Langjord, H.; Johansen, T.A. Dual-mode switched control of an electropneumatic clutch actuator. IEEE/ASME Trans. Mechatron. 2010, 15, 969-981. [CrossRef]

9. Zhong, Z.; Kong, G.; Yu, Z.; Chen, X.; Chen, X.; Xin, X. Concept evaluation of a novel gear selector for automated manual transmissions. Mech. Syst. Signal Process. 2012, 31, 316-331. [CrossRef]

10. Taguchi, Y.; Soga, Y.; Mineno, A.; Kuzuya, H.; Horiuchi, I.; Ueda, Y.; Miyazaki, T. Development of an Automated Manual Transmission System Based on Robust Design; SAE Paper 2003-01-0592; SAE International: Warrendale, PA, USA, 2003. [CrossRef]

11. Chen, Q.M.; Li, L.Y.; Wang, M.Y.; Pei, L. The precise modeling and active disturbance rejection control of voice coil motor in high precision motion control system. Appl. Math. Model. 2015, 39, 5936-5948. [CrossRef] 
12. Turner, A.J.; Ramsay, K.; Clark, R.E.; Howe, D. Development of High Force Electromechanical Linear Actuator for Shift-By-Wire Automated Manual Transmissions; SAE Paper 2006-01-0360; SAE International: Warrendale, PA, USA, 2006. [CrossRef]

13. Zhou, Y.; Chang, S. The control system design for direct-drive gearshift mechanism. In Proceedings of the FISITA 2016 World Automotive Congress, Busan, Korea, 26-30 September 2016.

14. Kim, J.; Lee, H. Motor position control algorithm for an automated manual transmission of the agricultural tractor. Proc. Inst. Mech. Eng. Part C J. Mech. Eng. Sci. 2015, 229, 3341-3349. [CrossRef]

15. Li, L.; He, K.; Wang, X.; Liu, Y. Sensor fault-tolerant control for gear-shifting engaging process of automated manual transmission. Mech. Syst. Signal Process. 2017, 99, 790-804. [CrossRef]

16. Hanson, B.; Levesley, M. Self-sensing applications for electromagnetic actuators. Sens. Actuators A 2004, 116, 345-351. [CrossRef]

17. Mercorelli, P. Robust feedback linearization using an adaptive PD regulator for a sensorless control of a throttle valve. Mechatronics 2009, 19, 1334-1345. [CrossRef]

18. $\mathrm{Xu}, \mathrm{Q}$. Digital sliding-mode control of piezoelectric micropositioning system based on input-output model. IEEE Trans. Ind. Electron. 2014, 61, 5517-5526. [CrossRef]

19. Zhao, L.; Huang, J.; Liu, H.; Li, B.; Kong, W. Second-order sliding-mode observer with online parameter identification for sensorless induction motor drives. IEEE Trans. Ind. Electron. 2014, 61, 5280-5289. [CrossRef]

20. Vieira, R.P.; Gastaldini, C.C.; Azzolin, R.Z.; Gründling, H.A. Sensorless sliding-mode rotor speed observer of induction machines based on magnetizing current estimation. IEEE Trans. Ind. Electron. 2014, 61, 4573-4582. [CrossRef]

21. Bernardes, T.; Montagner, V.F.; Gründling, H.A.; Pinheriro, H. Discrete-time sliding mode observer for sensorless vector control of permanent magnet synchronous machine. IEEE Trans. Ind. Electron. 2014, 61, 1679-1691. [CrossRef]

22. Mercorelli, P. An adaptive and optimized switching observer for sensorless control of an electromagnetic valve actuator in camless internal combustion engines. Asian J. Control 2014, 16, 959-973. [CrossRef]

23. Mercorelli, P. A Motion-Sensorless Control for Intake Valves in Combustion Engines. IEEE Trans. Ind. Electron. 2017, 64, 3402-3412. [CrossRef]

24. Mercorelli, P. A switching kalman filter for sensorless control of a hybrid hydraulic piezo actuator using mpc for camless internal combustion engines. In Proceedings of the IEEE International Conference on Control Applications, Dubrovnik, Croatia, 3-5 October 2012.

25. Mercorelli, P. A two-stage sliding-mode high-gain observer to reduce uncertainties and disturbances effects for sensorless control in automotive applications. IEEE Trans. Ind. Electron. 2015, 62, 5929-5940. [CrossRef]

26. Okada, Y.; Matsuda, K.; Hashitani, H. Self-sensing active vibration control using the moving-coil-type actuator. J. Vib. Acoust. 1995, 117, 411-415. [CrossRef]

27. Bai, M.R.; Wu, H. Robust control of a sensorless bass-enhanced moving-coil loudspeaker system. J. Acoust. Soc. Am. 1999, 105, 3283-3289. [CrossRef]

28. Zhang, J.; Chang, Y.; Xing, Z. Study on self-sensor of linear moving magnet compressor's piston stroke. IEEE Sens. J. 2009, 9, 154-158. [CrossRef]

29. Sung, J.W.; Lee, C.W.; Kim, G.S.; Lipo, T.A.; Won, C.Y.; Choi, S. Sensorless control for linear compressors. Int. J. Appl. Electromagnet. Mech. 2006, 24, 273-286.

30. Lin, S.; Chang, S.; Li, B. Improving the gearshifts events in automated manual transmission by using an electromagnetic actuator. Proc. Inst. Mech. Eng. Part C J. Mech. Eng. Sci. 2015, 229, 1548-1561. [CrossRef]

31. Phu, D.X.; An, J.H.; Choi, S.B. A Novel Adaptive PID Controller with Application to Vibration Control of a Semi-Active Vehicle Seat Suspension. Appl. Sci. 2017, 7, 1055. [CrossRef]

32. Song, B.K.; An, J.H.; Choi, S.B. A New Fuzzy Sliding Mode Controller with a Disturbance Estimator for Robust Vibration Control of a Semi-Active Vehicle Suspension System. Appl. Sci. 2017, 7, 1053. [CrossRef]

33. Chen, W.; Yang, J.; Guo, L.; Li, S. Disturbance-observer-based control and related methods-An overview. IEEE Trans. Ind. Electron. 2016, 63, 1083-1095. [CrossRef]

34. Chladny, R.R.; Koch, C.R. Flatness-based tracking of an electromechanical variable valve timing actuator with disturbance observer feedforward compensation. IEEE Trans. Control Syst. Technol. 2008, 16, 652-663. [CrossRef]

35. Han, J. Active Disturbance Rejection Control Technique; National Defense Industry Press: Beijing, China, 2008; ISBN 978-7-118-05795-9. 
36. Shi, X.; Chang, S. Precision motion control of a novel electromagnetic linear actuator based on a modified active disturbance rejection controller. Proc. Inst. Mech. Eng. Part I J. Syst. Control Eng. 2011, 226, 606-614. [CrossRef]

37. Lin, S.; Chang, S.; Li, B. Gearshift control system development for direct-drive automated manual transmission based on a novel electromagnetic actuator. Mechatronics 2014, 24, 1214-1222. [CrossRef]

38. Huang, Y.; Xue, W. Active disturbance rejection control: Methodology and theoretical analysis. ISA Trans. 2014, 53, 963-976. [CrossRef] [PubMed]

39. Chang, S.; Liu, L. A Moving Coil Permanent Magnet Linear Actuator with High Power Density. Patent CN101127474B, 14 July 2010.

(C) 2017 by the authors. Licensee MDPI, Basel, Switzerland. This article is an open access article distributed under the terms and conditions of the Creative Commons Attribution (CC BY) license (http://creativecommons.org/licenses/by/4.0/). 